\title{
The Outcome of Intrapartum Lamaze Philosophy in Low Risk Pregnant Women in Turkey
}

\author{
Reyhan ERKAYA* and Kıymet YESILÇIÇEK ÇALIK \\ Department of Obstetrics and Gynaecology Nursing, Faculty of Health Science, Karadeniz Technical \\ University, Trabzon, Turkey
}

*Corresponding author: Reyhan Erkaya, Department of Obstetrics and Gynaecology Nursing, Faculty of Health Science, Karadeniz Technical University, Trabzon, Turkey

\begin{abstract}
Background: The Lamaze philosophy identifies six care practices that promote, support, and protect normal birth. This study was conducted as descriptive research in order to determine whether normal childbirth actually occurs in keeping with the six points set forth in the philosophy of Lamaze.

Method: The study sample consisted of a total of 460 women. Data were collected over the period November 29, 2017 - June 30, 2018, in a hospital in northern Turkey after permission for the research was granted by the prevailing ethics committee. Used in collecting the data were a questionnaire on the participants' sociodemographic and obstetric features and a Lamaze technique assessment checklist that the author marked after making observations. Percentage distribution and means were used in the data analysis.
\end{abstract}

Results: The mean age of the women participating in the study was $28.48 \pm 7.41$ years. In the births reviewed in light of Lamaze philosophy, it was found that spontaneous labor was allowed (with no labor induction, 63.9\%; with no drugs to speed up labor, $88.7 \%$ ), women were supported throughout their labor to walk, move around, and change position $(92.6 \%)$ and were encouraged by healthcare personnel (95.4\%), and a loved one (her own mother, $32.6 \%$ ) of the expecting mother was allowed to be by her side $(92.4 \%)$

It was seen that unless medically required, no intervention was initiated such as restricting eating/drinking (76.5\%); enema (82.0\%), forceps/vacuum (99.6\%), epidural anesthesia $(95.4 \%)$, amniotomy $(63.0 \%)$, or continuous electronic fetal monitoring-EFM (96.3\%) was not performed and intravenous fluid was not administered (71.3\%), the mother and baby were kept together to encourage breastfeeding $(97.4 \%)$, and the infant was breastfed in the first 30 min. - 1 hour $(95.0 \%)$. It was however observed that $98.5 \%$ of the women delivered while lying in a supine, $49.5 \%$ were allowed to follow the body's urges to push, $50.9 \%$ underwent an episiotomy and fundal pressure was applied to $28.5 \%$.

Conclusion: It can be said based on the results of the study that the philosophy of Lamaze is generally supported in normal birth. Every woman needs to know that these six evidence-based birth practices make birth healthier and safer form others and babies.

\section{Keywords}

Normal childbirth, Natural childbirth, Intervention, The philosophy of lamaze

\section{Introduction}

'Lamaze', also known as psychoprophylaxis, is the most common method of preparation for childbirth [1]. Lamaze training is a birth philosophy rather than a technique. The Lamaze philosophy refers to a whole of practices such as informing and educating pregnant women before birth, supporting them during labor, providing relaxation and relief through breathing exercises. This philosophy aims to make normal birth natural, healthy, fearless, and happy by raising awareness of pregnant women emotionally and physically [2].

The Lamaze philosophy is based on a set of six Healthy Birth Practices, four of which were determined by WHO (World Health Organization) to support, protect and improve normal births and two of which were developed by Lamaze International to assist women's ability to give birth. The Lamaze philosophy suggests 
letting labor begin at its own pace, "letting women walk, move around and change positions throughout labor, letting a loved one (friend, spouse, or doula) support women continuously, *avoiding interventions that are not necessary medically, using upright pushing positions and following women's urges to push, keeping mother and baby together- which is better for mother, baby and breastfeeding ("marked practices were added by Lamaze International) [3,4].

This philosophy is also supported by Cochrane and the Coalition for Improving Maternity Services (CIMS). These evidence-based healthy birth practices, approved by Cochrane and CIMS, form the Lamaze philosophy at birth. This philosophy also establishes the normal birth standards of the Mother-Friendly Childbirth Initiative (MCFI).

The Lamaze philosophy aims at a normal, natural, and more humane birth that is respectful to the newborn baby from pregnancy to labor, especially at the time of labor. Lamaze training contributes positively to women, that is to say, it makes them feel calmer during childbirth, work actively for the health of their babies, trust their body and harmony with their babies, feel less pain with these techniques during contractions, and establish a much stronger bond with their babies immediately after birth [3].

\section{Materials and Methods}

\section{Aim}

The descriptive and cross-sectional type of the study intends to evaluate the normal births made in a Training and Research Hospital, which is located in the north of Turkey and takes the necessary initiatives to become a "Mother-Friendly Hospital" during the collection of study data, under the six items of the Lamaze philosophy.

\section{Patients and study design}

The population of this descriptive and cross sectionalstudy was the number of normal births (1474 births) that occurred in 2016 in a Training and Research Hospital located in the north of Turkey. The sample of the study was determined as 305 women by using the sample size formula $[\mathrm{n}=\mathrm{Nt} 2 \mathrm{pq} / \mathrm{d} 2(\mathrm{~N}-1)+\mathrm{t} 2 \mathrm{pq}](\mathrm{N}=$ $1474 p=0.5, q=0.5, t=1.96(\alpha=0.05), d=0.05)$, which is one of the probability sampling methods. The study sample was completed with 460 women enhancing the representation power of the universe and agreeing to participate in the study between 29-11-2017/3006-2018. The study was conducted with primiparas and multiparas who are between the ages of 18-49, between 37-41 weeks of gestation, and expected to have a natural spontaneous delivery, those who have a single fetus and a head presentation, and those who don't have any pregnancy complications and systemic diseases and communication problems. The pregnant women who were multiparas, had risky deliveries, had systemic diseases and had pregnancy complications were excluded.

\section{Data collection tools}

The study data were collected by a questionnaire developed by the researchers based on the literature [3-6]. During the data collection, each participant was informed about the researcher and the study, and their written and verbal consents were obtained. The data were gathered by monitoring the labor of women, who met the inclusion criteria to the study, from its latent phase to the postpartum period of two hours through face-to-face interviews and continuous observation techniques. The questionnaire includes two parts, one of which is about the socio-demographic characteristics of women ( 8 questions related to age, education, profession, work, place of residence, social security, family structure, income status, etc.) and their obstetric histories (5 questions related to the number of pregnancies, the number of living children, intended pregnancy status, the status of receiving pre and postnatal care, etc.) and was recorded through a face-to-face interview method by the researcherand the other of which evaluated six practices of the Lamaze philosophy [7] (1. Letting labor begin at its own pace, 2. Letting women walk, move around and change positions throughout labor, 3. Letting a loved one (friend, spouse, or doula) support women continuously, 4. Avoiding interventions that are not necessary medically, 5. Using upright pushing positions and following their bodies' urges to push, 6. Keeping mother and baby together, which is better for mother, baby, and breastfeeding) and was recorded as a checklist through continuous observation, following and evaluating in terms of Lamaze philosophy. In the data collection, while the face-toface interview lasted 10-15 minutes per participant, continuous observation time varied according to the total length of her birth time.

\section{Statistical analysis of data}

After the data collection process was completed, the data were input into the SPSS (Statistical Package for Social Sciences) for Windows 24.0 program and the data set was prepared for evaluation. The data were analyzed with descriptive statistics such as numbers, percentages, mean, and standard deviation.

\section{Results}

Table 1 shows the distribution of mothers' sociodemographic and obstetric characteristics. As can be seen, $50.9 \%$ of the women were in the $20-29$ age range, and the average age was $28.48 \pm 7.41$. It indicates that $45.2 \%$ of women were secondary or high school graduates, $65.2 \%$ were housewives, $66.5 \%$ did not work, $47.2 \%$ lived in the province, $58.8 \%$ perceived their income moderately, $94.1 \%$ had health insurance, $83.5 \%$ had a nuclear family, $35.2 \%$ had two or more 
Table 1: Analysis of socio-demographic and obstetric characteristics.

\begin{tabular}{|c|c|c|c|}
\hline \multicolumn{2}{|l|}{ Features } & \multirow{2}{*}{$\begin{array}{c}\mathbf{n} \\
46\end{array}$} & \multirow{2}{*}{$\begin{array}{c}\% \% \\
10.0\end{array}$} \\
\hline \multirow{3}{*}{ Age } & $15-19$ & & \\
\hline & $20-29$ & 234 & 50.9 \\
\hline & 30 and above & 180 & 39.1 \\
\hline Average age & \multicolumn{3}{|l|}{$28.48 \pm 7.41$} \\
\hline \multirow{3}{*}{ Education status } & Less than primary school education & 137 & 29.8 \\
\hline & Secondary School - High School & 208 & 45.2 \\
\hline & University and higher education & 115 & 25.0 \\
\hline \multirow{4}{*}{ Profession } & Housewife & 300 & 65.2 \\
\hline & Worker & 59 & 12.8 \\
\hline & Officer & 78 & 17.0 \\
\hline & Other & 23 & 5.0 \\
\hline \multirow{2}{*}{ Work status } & Working & 154 & 33.5 \\
\hline & Not working & 306 & 66.5 \\
\hline \multirow{3}{*}{ Place of residence for the longest time } & Village & 70 & 15.2 \\
\hline & Town-Province & 173 & 37.6 \\
\hline & City & 217 & 47.2 \\
\hline \multirow{3}{*}{ Income status } & Low income & 100 & 21.7 \\
\hline & Middle income & 309 & 67.2 \\
\hline & High income & 51 & 11.1 \\
\hline \multirow{2}{*}{ Social security } & Yes & 433 & 94.1 \\
\hline & No & 27 & 5.9 \\
\hline \multirow{2}{*}{ Family structure } & Extended family & 76 & 16.5 \\
\hline & Nuclear family & 384 & 83.5 \\
\hline \multirow{3}{*}{ Number of pregnancies } & 1 & 159 & 34.6 \\
\hline & 2 & 139 & 30.2 \\
\hline & 3 and more & 162 & 35.2 \\
\hline \multirow{3}{*}{ Number of living children } & No child & 20 & 4.3 \\
\hline & 1 & 322 & 70.0 \\
\hline & 2 and more & 118 & 25.7 \\
\hline \multirow{2}{*}{ Intended Pregnancy Status } & Yes & 375 & 81.5 \\
\hline & No & 85 & 18.5 \\
\hline \multirow{2}{*}{ Prenatal Education/Information Status } & Yes & 234 & 50.9 \\
\hline & No & 226 & 49.1 \\
\hline \multirow[t]{2}{*}{ Postnatal Care Education/Information Status } & Yes & 379 & 82.4 \\
\hline & No & 81 & 17.6 \\
\hline
\end{tabular}

pregnancies, $35.2 \%$ had three or more children, and $81.5 \%$ intended pregnancy. In addition, $50.9 \%$ of women received training and information about prenatal care and $82.4 \%$ for postpartum care.

Table 2 includes the analysis of normal births of women according to the Lamaze philosophy. According to the philosophy of letting birth begin at its own pace, it was found that $63.9 \%$ of women did not undergo induction and $88.7 \%$ of them did not use drugs to accelerate the birth. From the perspective of the philosophy of walking, moving, and changing positions during birth, it was determined that $92.4 \%$ of women walked during delivery, $92.6 \%$ moved, $92.6 \%$ changed positions, and $95.4 \%$ were encouraged by health personnel.
In terms of the philosophy of letting a loved one (friend, spouse, or doula) support women continuously, it was found that $92.4 \%$ of the women were supported by a loved one at birth (32.6\% mother, $29.6 \%$ sister, $7.6 \%$ mother-in-law, respectively).

From the perspective of the philosophy of avoiding interventions such as restriction of eating/drinking, enema, forceps, vacuum, episiotomy, epidural anesthesia, and continuous EFM, etc. unless medically necessary, it was found that $76.5 \%$ of women received liquid/nutrient, $82.0 \%$ were not applied enema, forceps (100\%) were not used, a vacuum (99.6\%) was not used, an episiotomy (50.9\%) was not made, epidural anesthesia (95.4\%) was not applied, continuous EFM 
Table 2: Analysis of normal births according to the Lamaze philosophy.

\begin{tabular}{|c|c|c|c|}
\hline & & $\begin{array}{c}\text { Yes } \\
\text { n (\%) }\end{array}$ & $\begin{array}{c}\text { No } \\
\text { n (\%) }\end{array}$ \\
\hline \multirow{2}{*}{$\begin{array}{l}\text { 1. Letting labor begin at its own } \\
\text { pace }\end{array}$} & Induction & $166(36.1)$ & $294(63.9)$ \\
\hline & Are there other drugs used to accelerate labor?* & $52(11.3)$ & $408(88.7)$ \\
\hline \multirow{4}{*}{$\begin{array}{l}\text { 2. Letting women walk, move } \\
\text { around and change positions } \\
\text { throughout labor }\end{array}$} & Does the pregnant woman walk during labor? & $425(92.4)$ & $35(7.6)$ \\
\hline & Does the pregnant woman move? & $426(92.6)$ & $34(7.4)$ \\
\hline & Does the pregnant woman change positions? & $426(92.6)$ & $34(7.4)$ \\
\hline & Is the pregnant woman encouraged by health personnel? & $436(95.4)$ & $24(4.6)$ \\
\hline \multirow{2}{*}{$\begin{array}{l}\text { 3. Letting a loved one (friend, } \\
\text { spouse, or doula) support women } \\
\text { continuously }\end{array}$} & Is there a loved one to support the expectant mother at birth? & $425(92.4)$ & $35(7.6)$ \\
\hline & $\begin{array}{l}\text { If yes, please specify who? } \\
\text { Mother } \\
\text { Sister } \\
\text { Spouse } \\
\text { Mother-in-law } \\
\text { Other }{ }^{*}\end{array}$ & $\begin{array}{l}151(32.6) \\
136(29.6) \\
21(4.6) \\
35(7.6) \\
117(25.7)\end{array}$ & \\
\hline \multirow{11}{*}{$\begin{array}{l}\text { 4. Avoiding interventions such } \\
\text { as restriction of eating/drinking, } \\
\text { enema, forceps, vacuum, } \\
\text { episiotomy, epidural anesthesia } \\
\text { and continuous EFM, etc. unless } \\
\text { medically necessary }\end{array}$} & Restriction of eating/drinking & $108(23.5)$ & $352(76.5)$ \\
\hline & Enema & $85(18.0)$ & $375(82.0)$ \\
\hline & Forceps & - & 100 \\
\hline & Vacuum & $2(0.4)$ & $458(99.6)$ \\
\hline & Episiotomy & $228(49.1)$ & $232(50.9)$ \\
\hline & Epidural anesthesia & $21(4.5)$ & $439(95.4)$ \\
\hline & Continuous EFM & $17(3.7)$ & $443(96.3)$ \\
\hline & Amniotomy & $170(37.0)$ & $290(63.0)$ \\
\hline & Intravenous fluid insertion & $134(28.7)$ & $326(71.3)$ \\
\hline & Drug use for analgesia (for pain etc.) & $298(64.8)$ & $162(35.2)$ \\
\hline & Number of touch/vaginal examinations & $95(20.7)$ & $365(79.3)$ \\
\hline \multirow{5}{*}{$\begin{array}{l}\text { 5. Using upright pushing positions } \\
\text { and following women's urges to } \\
\text { push }\end{array}$} & Is the position of the pregnant woman on her back at birth? & $453(98.5)$ & $7(1.5)$ \\
\hline & Is fundal pressure applied during birth? & $131(28.5)$ & $329(71.5)$ \\
\hline & Is it open glottis pushing? & $135(29.3)$ & $325(70.7)$ \\
\hline & Is it closed glottis pushing? & $114(24.8)$ & $346(75.2)$ \\
\hline & Is the pregnant woman made to push by herself? & $211(45.9)$ & $249(54.1)$ \\
\hline \multirow{4}{*}{$\begin{array}{l}\text { 6. Keeping mother and baby } \\
\text { together to promote mother-baby } \\
\text { bonding and support breastfeeding } \\
\text { after birth }\end{array}$} & $\begin{array}{l}\text { Has the baby been given to the mother immediately after } \\
\text { birth? }\end{array}$ & $437(95.0)$ & $23(5.0)$ \\
\hline & Has skin-to-skin contact been practiced? & $436(94.8)$ & $24(5.2)$ \\
\hline & $\begin{array}{l}\text { Has the baby been breastfed in the first } 30 \text { minutes- } 1 \text { hour } \\
\text { after birth? }\end{array}$ & $438(95.2)$ & $22(4.8)$ \\
\hline & $\begin{array}{l}\text { Are the mother and baby in the same room in the early } \\
\text { postpartum period after birth? }\end{array}$ & $448(97.4)$ & $12(2.6)$ \\
\hline
\end{tabular}

*: Antispasmodics; " : Friend, aunt, neighbor.

(96.3\%) was not applied, amniotomy (63.0\%) was not performed, intravenous fluid (71.3\%) was not inserted and vaginal examination $(79.3 \%)$ was not performed. It was determined that $64.8 \%$ of the women were used drugs for analgesia (Table 2).

According to the philosophy of using upright pushing positions and following their bodies' urges to push, it was determined that $98.5 \%$ of the women gave birth in the upright position, $71.5 \%$ of them were not applied fundal pressure, $45.9 \%$ of them pushed on their own, $29.3 \%$ of them had open glottis pushing and $24.8 \%$ of them had closed glottis pushing.

In terms of the philosophy of keeping mother and baby together to promote mother-baby bonding and support breastfeeding after birth, it was determined that $95.0 \%$ of women were given the baby immediately after birth, $94.8 \%$ of them had skin-to-skin contact, $95.2 \%$ of their babies were breastfed within the first 30 minutes-1 
hour and $97.4 \%$ of them were in the same room in the early postpartum period after birth (Table 2).

\section{Discussion}

Lamaze International believes that "every woman should be free to give birth safely, be free to choose methods that will provide her comfort, and be supported by both her family and healthcare team members who trust her and her ability to give birth". In this context, it has defined six care practices to support normal birth [7]. The findings of this study were discussed according to these principles.

It is stated that socio-demographic characteristics affect health perception, development, and healthy lifestyle behaviors $[8,9]$. The mean age of the women in this study is $28.4 \pm 41$ years, and it is observed that the majority of them are secondary school and high school graduates, unemployed, multiparas, live in the city center, and have a nuclear family structure, have social security, and have a medium level of family income perception. According to the 2018 data of the Turkey Population Health Survey, the fact that the majority of women in our society have a low level of education, do not work, and the temporal change in the age-specific total fertility rate increases in the age range of 25-29 supports the findings of the study [10]. In addition, in this study, it is found out that only half of the women received prenatal education. However, it is known that through the information and support provided by the education received in the prenatal period, it is known that the woman and her husband are prepared physically, socially, and psychologically for the birth and postpartum period $[3-5,10]$. In addition, although, with the Pregnancy Information Class Circular No. 2014/28 published by the Public Health Institution of Turkey, the effort to provide free education to more pregnant women is increasing each year [11], it has been reported that women do not attend pregnancy (preparation for childbirth) education classes in studies [3-5]. Nevertheless, these classes aim to make the birth experience more positive by giving women skills such as focusing on their own body and coping with labor pain, with different philosophies and relaxation techniques such as Lamaze, Dick-Read, Hypnobirthing, Bradley $[2,4,12]$.

The World Health Organization (WHO) and the National Institute of Health and Clinical Excellence (NICE) do not recommend applications such as oxytocin and antispasmodic to accelerate labor in the first stage of labor [13-15]. Likewise, the Lamaze philosophy advocates that labor should begin at its own pace, that induction should not be applied unless medically necessary, and that each mother's body and baby should be respected $[3,7]$ because it emphasizes that induction-induced birth will become a medical event and will proceed quite differently from spontaneous birth [7]. Studies have shown that induction of labor without medical indication increases the frequency of intrapartum interventions, the length of hospital stay, the risk of postpartum hemorrhage and neonatal morbidity, the need for epidural anesthesia and cesarean section, it restricts freedom of movement, and reduces satisfaction [16-19]. However, studies have reported that almost half of women were used induction to initiate labor $[16,20,21]$. In this study, it was determined that drugs such as induction application and antispasmodic to accelerate labor were used more than $10 \%$ [14], the rate which is determined by WHO for induction, but that is less than other studies' findings $[16,20,21]$. It can be said that this is because the hospital where the study was conducted has completed its preparations to become a mother-friendly hospital, the delivery room team has completed in-service training accordingly and induction is applied restrictively, which is one of the mother-friendly hospital goals.

Walking, moving, and changing positions during birth make the birth easier and safer. Therefore, WHO, the Royal College of Midwives (RCM), and The Coalition for Improving Maternity Services (CIMS) recommend that pregnant women should be allowed to walk, move freely and change positions during labor [13,22-24]. Lamaze also offers suggestions such as shower, exercise balls, $\mathrm{CD}$ players for music, telemetry that allows movement during EFM, which will encourage women to move during labor [7]. In this study, it was determined that women were encouraged to walk, move and change positions during labor by the health personnel. In the studies, it is stated that the benefits of upright positions should be explained to women as much as possible, they should be encouraged to change positions every 30 minutes by assisting them to choose the positions that suit them, and free movement options should not be restricted unless there is a clinical obstacle [25-28].

In almost every culture, women were often supported by friends, relatives, or other women during labor $[29,30]$. WHO recommends that emotional and physical support be provided to pregnant women during birth by a loved one (spouse, friend, etc.) [13]. Lamaze also states that the presence of a loved one with pregnant women during the labor process and the physical support $s /$ he will provide lessens pain and emotional support reduces stress, so the labor will be safer, healthier, easier, it will end up without medical intervention and with higher satisfaction [7]. In this study, it was determined that women were constantly supported by a loved one (mother, sister, mother-inlaw, respectively) during labor. Studies have shown that continuous support during labor shortens the duration of labor, reduces the rates of interventional vaginal and cesarean delivery, perineal trauma, postpartum depression, and anxiety, increases satisfaction and Apgar scores, enables women to cope better with labor pains, and prolongs breastfeeding duration [29,30]. 
WHO, Lamaze, and CIMS recommend avoiding all medically unnecessary interventions (such as restriction of eating/drinking, enemas, forceps, vacuum, episiotomy, epidural anesthesia, and continuous EFM, etc. during labor) $[7,13,23]$. Their use should be avoided unless there is a medical reason because it is stated that unnecessary medical interventions interfere in the natural process of labor and cause maternal and neonatal complications by posing another intervention $[17,18,20,21]$. In this study, while oral fluid/nutrient restriction, continuous EFM, amniotomy, enema, touch/ vaginal examination, intravenous fluid, analgesic drugs, vacuum-forceps, and epidural anesthesia were not applied to the majority of pregnant women, a significant portion of them were administered analgesia drugs and half of them underwent episiotomy. However, contrary to our study findings, in the literature, it is seen that medical interventions at birth are routinely applied to all pregnant women regardless of high-risk and lowrisk pregnant women $[17-19,21]$. In their study named "The effect of interventions in labor on maternal satisfaction" in the same hospital where this study was conducted (before it became a mother-friendly hospital), Yeşilçiçek Çalık, et al. showed that interventions applied at high rates negatively affected women's birth satisfaction [20]. Therefore, it is thought that the low frequency of interventions in our study results is because the hospital where the study was conducted is about to receive the title of mother and baby-friendly hospital and that all interventions made during the labor process with mother-friendly hospital practices are based on scientific evidence. Apart from these positive developments, it is observed that episiotomy rates are still well above the rate determined by $\mathrm{WHO}$ (10\%) [14] (49.1\%). This may result from the fact that episiotomy is applied to primiparas traditionally on a routine basis, and episiotomy is employed to multiparas when necessary in our country. Also, it is thought that this is due to the possibility of recurrent episiotomy indication since most of the women in our study were multiparas.

WHO and CIMS suggest that other positions should be preferred instead of the upright position during labor and that women should watch their own bodies while pushing $[13,23]$. Lamaze also argues that all phases of labor will be shorter and easier for the mother and baby, as upright positions in the second stage of labor allow to take advantage of the effect of gravity and keep the pelvic bones loose and open [7]. However, in this study, it was determined that women gave birth in the upright position.Still, studies have shown that using upright positions in the second stage of labor is beneficial in improving the outcomes related to mother and newborn and dealing with some obstetric complications, as it reduces the incidence of fetal distress and the need for cesarean section and epidural analgesia, increases the satisfaction of women, and decreases the incidence of episiotomy and interventional delivery during the second stage of labor [25,31,32]. Although the upright position in labor causes a decrease in placental blood flow and the efficiency of uterine contractions, it is widely employed because it provides convenience to health personnel. Out-of-hospital deliveries are not prevalent in our country, and practices are incorporated into hospital conditions. Therefore, it seems that the tradition of performing labor in the upright position will continue in many countries of the world where hospitals are mother-baby friendly.

In this study, as in Lamaze's proposal "to watch your body while pushing, it was also determined that most of the women pushed spontaneously (open glottis) and/ or with their own pushing technique, and no fundal compression was applied [7]. The best clinical practice that can be accepted in evidence-based guidelines is to support spontaneous pushing and encourage women to choose their own pushing technique $[8,33,34]$.

Mothers and babies need to be together physiologically at the time of birth and in the following hours and days. Keeping mothers and babies together is a safe and healthy birth practice [35]. WHO, Lamaze, and CIMS recommend that mother-baby bonding should be ensured after birth and that mother and baby should stay together $[7,13,23]$. This sensitive time, sometimes called the "magical hour," "golden hour," or "sacred hour," requires respect, protection, and support [35]. In this study, it was determined that the baby was given to the mother immediately after birth, skin-to-skin contact was provided, the baby was breastfed within the first 30 minutes- 1 hour, and the mother and the baby were in the same room in the early postpartum period, as suggested by both Lamaze and other international organizations. Providing mother-baby bonding after birth is one of the mother-friendly hospital practices. Early skin-to-skin contact is of great importance for the establishment of this bond, and it is particularly encouraged to be implemented by mother-friendly hospitals. In a study conducted in the United States, it is observed that this incentive increases significantly in both vaginal and cesarean deliveries [36]. As a matter of fact, it was stated in the studies that skin-to-skin contact in the early period reduces the baby's crying, has a positive effect on breastfeeding success, breastfeeding self-efficacy, breast milk intake, and has positive effects on the heart and respiratory system [35-39].

\section{Conclusion}

As a result, three of the six practices that Lamaze recommends regarding care to support normal birth in the hospital where the deliveries take place (walking, moving, and changing positions during birth; letting a loved one support mother at birth; providing motherbaby bonding after birth and supporting breastfeeding. keeping mother and baby together) are fully adopted. It can be said that the other two are frequently 
performed (not intervening unless medically necessary and watching the body pushing), but only one of them (avoiding giving birth on the back) is not practiced, so normal births are mostly carried out in support of the Lamaze's philosophy.

Therefore, intrapartum care is a defined reproductive right for all women, where the dignity, privacy, and confidentiality of women are protected, they are constantly supported during labor, harm and ill-treatment are prevented, they are allowed to make informed choices, and they have the experience of positive birth and care [13]. A holistic approach must be adopted to get this right to women.

\section{Ethical Statement}

The study was carried out under the World Medical Association Declaration of Helsinki (2013) [10]. The necessary institutional permission (approval number 63582098/299-E.143) and ethical institution permission (approval number 23618724/2017/62) were obtained for the study. Written informed consent was obtained from the women who were included in the study sample.

\section{Limitations}

The study has some limitations. First, the results cannot be generalized because the sample size is small, the study was conducted at a hospital and answers were self-reportedly given. Therefore; multicentric studies with large sample sizes are required.

\section{Conflict of Interest}

The authors have no conflicts of interest to disclose.

\section{Acknowledgments}

We would like to thank Midwife Meryem REis who contributed to the data collection phase of the study. The authors thank all the women who participated in this study.

\section{Funding}

This study was presented by $2^{\text {nd }}$ International and $3^{\text {rd }}$ National Congress of Postpartum Care, Konya, Turkey.

\section{References}

1. Walker DS, Visger JM, Rossie D (2009) Contemporary childbirth education models. J Midwifery Womens Health 54: 469-476.

2. Pain R (2002) Lamaze International. J Perinat Educ 11: $\mathrm{X}$-xii.

3. Coşar F, Demirci N (2012) The effect of education of pregnant women in child birth education classes based on the philosophy of lamaze on perception and orientation of birth process. Süleyman Demirel Üniversitesi Sağlık Bilimleri Dergisi 3: 18-30.

4. Samiye M, Ertuğrul M, Uludağ E (2015) A childbirth preparatory training program: awareness in childbirth. Dokuz Eylül University 8: 131-141.

5. Onat G, Şahin N (2010) Childbirth education models and current approaches. Journal of Education and Research in Nursing 7: 36-43.

6. Romano AM, Lothian JA (2008) Promoting, protecting, and supporting normal birth: A look at the evidence. J Obstet Gynecol Neonatal Nurs 37: 94-105.

7. (2009) Lamaze Healthy Birth Practices. Lamaze Internatioanal.

8. Bilgili N, Ayaz S (2009) Health promotion behaviors of women and affecting factors. TAF Preventive Medicine Bulletin 8.

9. Özcan H, Polat T, Yılmaz M, Öztürk A, Aydoğan T (2020) Determination of healthy life behaviors and affecting factors in pregnant women. Online Turkish Journal of Health Sciences 5: 482-492.

10. (2018) Turkey Demographic and Health Survey (TNSA). Hacettepe UniversityInstitute of Population Studies, Ankara.

11. T.C. Ministry of Health Pregnant School Circular, $99910406-$ 799.

12. Spinelli A, Baglio G, Donati S, Grandolfo ME, Osborn J (2003) Do antenatal classes benefit the mother and the baby? J Matern Fetal Neonatal Med 13: 94-101.

13. (2018) WHO recommendations: Intrapartum care for a positive child birth experience. World Health Organization, Geneva.

14. (2018) WHO recommendations: Induction of labour at or beyond term. World Health Organization, Geneva.

15. NICE (2016) Intrapartum care or healthy women and babies. Natioanal Institue for Health and Care Excellence.

16. Gülmezoglu AM, Crowther CA, Middleton $P$, Heatley $E$ (2012) Induction of labour for improving birth outcomes for women at or beyond term. Cochrane Database of Systematic Reviews, Issue 6: CD004945.

17. Prado DS, Mendes RB, Gurgel RQ, Barreto IDDC, Bezerra FD, et al. (2017) Practices and obstetric interventions in women from a state in the Northeast of Brazil. Revista da Associação Médica Brasileira 63: 1039-1048.

18. Weeks F, Pantoja L, Ortiz J, Foster J, Cavada G, et al. (2017) Labor and birth care satisfaction associated with medical interventions and accompaniment during labor among Chilean women. Journal of Midwifery \& Women's Health 62: 196-203.

19. Taheri M, Takian A, Taghizadeh Z, Jafari N, Sarafraz $N$ (2018) Creating a positive perception of child birth experience: Systematic review and meta-analysis of prenatal and intrapartum interventions. Reprod Health 15: 73.

20. Çalik KY, Karabulutlu Ö, Yavuz C (2018) First do noharm - Interventions during labor and maternal satisfaction: A descriptivecross-sectionalstudy. BMC Pregnancy Childbirth 18: 1-10.

21. Gu C, Wang X, Zhang Z, Schwank S, Zhu C, et al. (2020) Pregnant women's clinical characteristics, intrapartum interventions, and duration of labour in urban China: a multi-center cross-sectional study. BMC Pregnancy and Childbirth 20: 1-10.

22. The Royal Collage Midwives (RCM) (2010) The Royal College of Midwives Survey of Positions used in Labour and Birth Final Report. London.

23. (2007) Mother-Friendly Childbirth - Highlights of the Evidence. 
24. Hotelling BA (2007) The coalition for improving maternity services: Evidence basis for the ten steps of mother-friendly care. TheJournal of Perinatal Education 16: 38-43.

25. Ondeck M (2014) Healthy Birth Practice \#2: Walk, Move Around, and Change Positions Throughout Labor. J Perinat Educ 23: 188-193.

26. Barasinski C, Debost-Legrand A, Lemery D, Vendittelli $F$ (2018)Positions during the first stage and the passive second stage of labor: A survey of French midwives. Midwifery 56 : 79-85.

27. Souza JP, Miquelutti MA, Cecatti JG, Makuch MY (2006) Maternal position during the first stage of labor: A systematic review. Reproductive Health 3: 1-9.

28. Lawrence A, Lewis L, Hofmeyr GJ, Styles C (2013) Materna positions and mobility during first stage labour. Cochrane Database Syst Rev 10.

29. Bohren MA, Hofmeyr GJ, Sakala C, Fukuzawa RK, Cuthbert A (2017) Continuous support for women during childbirth. Cochrane Database of Systematic Reviews 7.

30. Lunda P, Minnie CS, Benadé P (2018) Women's experiences of continuous support during childbirth: a meta-synthesis. BMC Pregnancy and Childbirth 18: 167.

31. Berta M, Lindgren $\mathrm{H}$, Christensson K, Mekonnen S, Adefris M (2019) Effect of maternalbirthpositions on duration of secondstage of labor: Systematicreviewand meta-analysis. BMC Pregnancyand Childbirth 19: 1-8.

32. Deliktas A, Kukulu K (2018) A meta-analysis of the effect on materna health of upright positions during the second stage of labour, without routine epidural analgesia. Journal of Advanced Nursing 74: 263-278.
33. Sandström A, Altman M, Cnattingius $S$, Johansson $S$, Ahlberg M, et al. (2017) Durations of second stage of labor and pushing, and adverse neonatal outcomes: a populationbased cohort study. Journal of Perinatology 37: 236-242.

34. Szu LT, Chou PY, Lin PH, Chen C, Lin WL, et al. (2020) Comparison of maternal and fetal outcomes between delayed and immediate pushing in the second stage of vaginal delivery: Systematic review and meta-analysis of randomized controlled trials. Archives of Gynecology and Obstetrics 303: 481-499.

35. Crenshaw JT (2019) Healthy Birth Practice \#6: KeepMother and Baby Together- It's Best for Mother, Baby, and Breastfeeding. J Perinat Educ 23: 211-217.

36. Boundy EO, Perrine CG, Barrera CM, Li R, Hamner HC (2018) Trends in Maternity Care Practice Skin-to-Skin Contact Indicators: United States, 2007-2015. Breastfeed Med 13: 381-387.

37. Moore ER, Bergman N, Anderson GC, Medley N (2016) Early skin-to-skin contact form others and their healthy newborn infants. Cochrane Database Syst Rev 11: CD003519.

38. Crenshaw JJ (2007) Care practice \#6: no separation of mother and baby, with unlimited opportunities for breastfeeding. Perinat Educ 16: 39-43.

39. Adeli M, Aradmehr M (2018) A comparative study of maternal-neonate abdominal and kangaroo (skin-to-skin) skin contact immediately after birth on maternal attachment behaviors upto 2 months. Journal of Education and Health Promotion 7: 42. 